SEREDA B.P., Prof., D.Sc.

GAIDAENKO A.S.*, General director MAKSIMENKO O.P., Prof., D.Sc. SEREDA D.B., PhD.

Dniprovsky State Technical University, Kamianske

*Private joint-stock company Yuzkoks, Kamianske

\title{
RESEARCH OF CORROSION RESISTANCE OF MATERIALS WORKING IN COAL RESIN AND FORMATION OF SEDIMENTS BEFORE GRINULATION OF THE PERK
}

Introduction. Corrosion resistance of structural materials working in conditions of sulfate solutions is an important factor in the performance of aggregates and mechanisms of coke production. The use of materials that resist corrosion in aggressive environments can significantly increase the economic efficiency of production.

Statement of the problem. It is known that the instability of loading chemical workshops of coke production, a sharp change in the productivity of units due to instability of the coke base, an increase in the HCN content in coke oven gas (due to a decrease in the content of bottom coal with a low nitrogen content in the charge), the use of new reagents for water purification closed water supply cycles increase the corrosiveness of process fluids. The growing use of imported equipment necessitates more careful monitoring of local corrosion, which is the most dangerous. When it develops in places where metal fatigue occurs, cracks or stress corrosion cracking occur. With this type of damage, the service life of the equipment is significantly reduced.

Results of work. In this work, we studied the corrosion resistance of steels operating in environments in the environment of coal tar sulfate department of PJSC „Zaporozhkoks”. Now in the coke industry, the problem of corrosion protection of welded joints in the equipment of sulfate compartments is most acute. The aggressive environment of sulfate compartments is the mother liquor, which includes: sulfuric acid, ammonium sulfate, chlorides.

According to the researchers, the content of mineral salts in technological solutions and in coke oven gas with an almost complete absence of $\mathrm{O}_{2}$ complicates the formation of protective passive films on the surface of chromium-nickel steels, and leads to the occurrence of local types of corrosion damage (ulcers and pitting). In addition, the course of corrosion processes is stimulated by an elevated temperature and the speed of movement of solutions $[1,2]$.

Corrosion-resistant austenitic-ferritic (duplex corrosion-resistant steels DKS), consist of two main phases - austenite and ferrite in approximately equal amounts (but not less than $30 \%$ each). Both of these phases are corrosive due to their high chromium content. This structure provides a good combination of reinforcing and plastic properties, and is also resistant to intergranular and chiseled-ulcerative corrosion. In the study of the causes of precipitation before pitch granulation, such a problem arises, due to clogging of the nozzle plate holes and filters, the volume of variable production decreases. During the study, precipitation samples were taken, which were analyzed using a Neophot-32 microscope in reflected light, according to the technique in reflected rays (polarized).

The filter cake before granulation is shown in Fig.1.

Based on the results of the analysis of samples established.

1. The content of substances insoluble in quinoline and toluene in the filter cake sample before granulation (35.4 and 50\%) indicates the presence of high-pyrolyzed particles with a size of 27-48 microns, which are formed, possibly, when the resin passes through a tube furnace or during oxidation in a cube the reactor. 


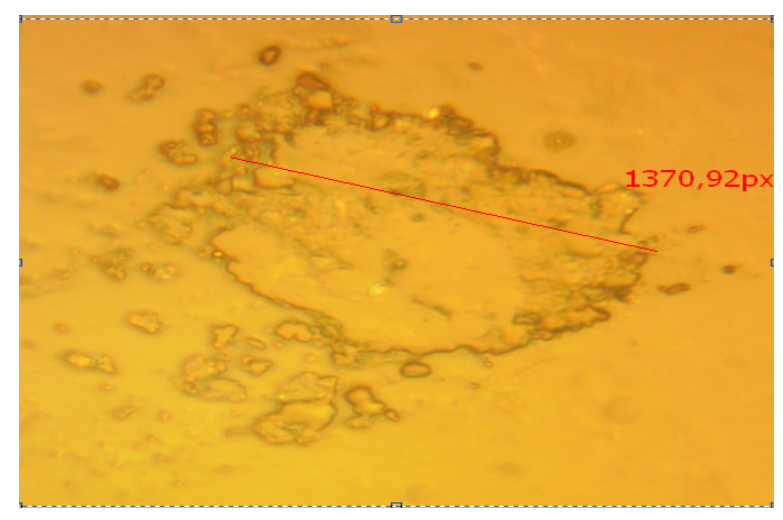

a

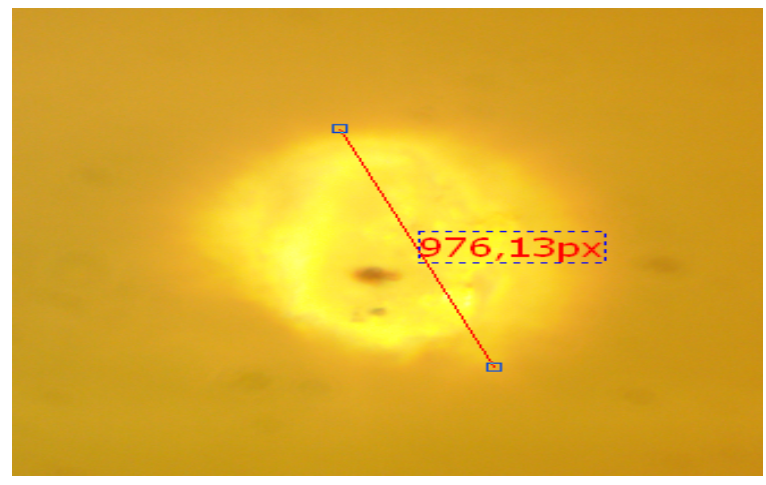

c

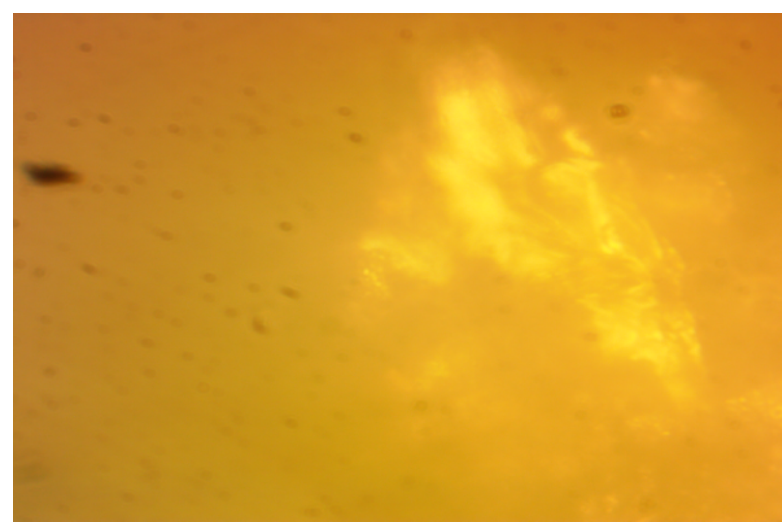

b

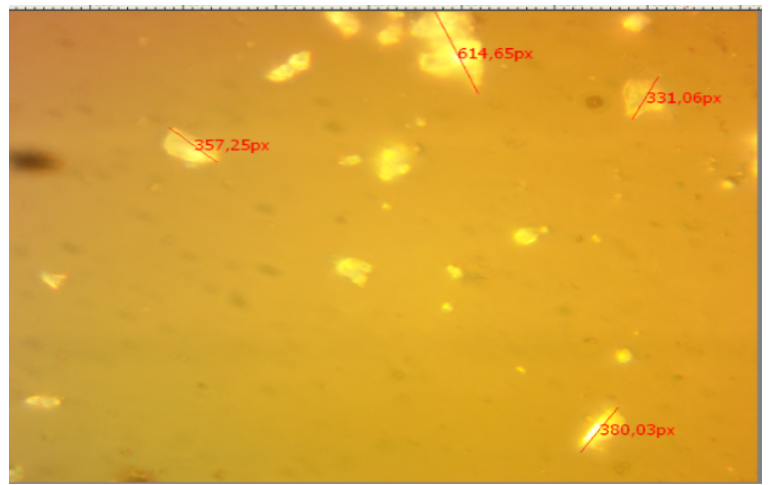

$\mathrm{g}$

a - amorphous fraction with a size of $45 \times 48 \mu \mathrm{m}$ with small inclusions of ash (filter cake);

$\mathrm{b}$-ash fraction after sedimentation ashing; $\mathrm{c}$ - mineral fraction with a size of 31 microns

(filter cake); g-mineral particles with a size of 10-20 microns (filter cake)

Figure 1 - Characterization of filter cake before granulation

2. A high ash content of the precipitate on the filter before granulation was noted $(2.59 \%)$, which is caused by the adhesion of ash particles on the precipitation during filtration (dots glowing in part of Fig.1).

3. Detected ash particles having the correct pointed shape, 5-30 microns in size, which can cause abrasive wear.

Microscopic studies of precipitation from the filter in front of Legrand showed that the size of the high-pyrolyzed particles was 80-100 microns.

Analysis of the test results of steel samples 45 with alloyed $\mathrm{Cr}$, Ti, Si aluminized coatings installed in a Legrand granulator [3,4] (Table 1) showed high corrosion resistance of alloyed alloys obtained under SHS conditions.

Table 1 - Comparative stability of structural materials in the granulator of Legrand pitch

\begin{tabular}{|c|c|c|}
\hline \multirow{2}{*}{ Material } & \multicolumn{2}{|c|}{ Corrosion rate, $\mathrm{mm} /$ year } \\
\cline { 2 - 3 } & I testing & II testing \\
\hline BCT-3 & 1,4215 & 1,7281 \\
\hline low-alloy cast iron & 0,5219 & - \\
\hline 15X5M & 0,1804 & 0,1855 \\
\hline Al-Cr (steel 45) & 0,0117 & 0,0105 \\
\hline Al-Ti (steel 45) & 0,0102 & 0,0118 \\
\hline Al-Si (steel 45) & 0,01056 & 0,0178 \\
\hline 12X18H10T & 0,0117 & 0,0174 \\
\hline
\end{tabular}


The study of the stability of structural materials in coal tar environments, despite the difficulties of modeling corrosion processes and environments in laboratory conditions, the research methodology is based on determining the corrosion rate in an industrial environment. Samples of various materials $60 \times 60 \mathrm{~mm}$ in size, after degreasing and weighing, were hung in the apparatus of the operating units of the tar distillation shop $[5,6]$.

After testing, the samples were removed from the apparatus, the weight reduction was determined, and the average corrosion rate was calculated from it. The investigated materials were: carbon steel (BCt.3), cast iron (SCh15), chrome cast iron, steel 45 with alloyed aluminous coatings, alloyed steel.

Based on the results of Table 3, it was found that it is possible to replace alloy steels 15X5M, 08X13, 08X22H6T with steel 45 with alloyed $\mathrm{Cr}$, Ti, and Si alloyed coatings. In an evaporator of the second degree, samples of steel St.3 and other materials were hung at the inlet pipe supplying resin vapors to the apparatus. The results of the corrosion tests of witness samples in the evaporator of the tar distillation plant are given in table 2 [7].

Table 2 - Comparative aggressiveness of the media of distillation distillation columns in a second-degree evaporator

\begin{tabular}{|c|c|c|}
\hline \multirow{2}{*}{ Material } & \multicolumn{2}{|c|}{ Corrosion rate, mm / year } \\
\cline { 2 - 3 } & I testing & II testing \\
\hline BCT-3 & 3,4515 & 2,7781 \\
\hline low-alloy cast iron & 0,6219 & - \\
\hline 15X5M & 0,0804 & 0,0855 \\
\hline A1-Cr (steel 45) & 0,0147 & 0,0305 \\
\hline Al-Ti (steel 45) & 0,0152 & 0,0318 \\
\hline Al-Si (steel 45) & 0,0156 & 0,0378 \\
\hline $08 X 13$ & 0,0110 & 0,0296 \\
\hline $08 X 22 \mathrm{H} 6 \mathrm{~T}$ & 0,01314 & 0,0198 \\
\hline 12X18H10T & 0,00517 & 0,0074 \\
\hline
\end{tabular}

The study of the corrosion activity of the resin fractions showed that the most aggressive is the anthracene fraction. The ability to effectively protect materials from corrosion was confirmed by coatings obtained under the conditions of self-protective high-temperature synthesis [8-15]. The corrosion rate of steel decreases along the height of the column with decreasing temperature, with the possible exception of the naphthalene fraction, where the corrosion rate is greater than in the absorption fraction. This pattern is most likely related to the reactivity of sulfur compounds with increasing temperature and their concentration in coal tar fractions. Thus, corrosion tests have shown that with sufficient soda protection, the effect of sulfur compounds on corrosion resistance is greater than mineral salts

Conclusions. 1. The content of substances insoluble in quinoline and toluene in the filter cake sample before granulation (35.4 and 50\%) indicates the presence of high-pyrolyzed particles with a size of $27-48$ microns, which are formed, possibly, when the resin passes through a tube furnace or during oxidation in a cube the reactor.

2. A high ash content of the precipitate on the filter before granulation was noted $(2.59 \%)$, which is caused by the adhesion of ash particles on the precipitation during filtration (dots glowing in part of Fig.1).

3. Detected ash particles having the correct pointed shape, 5-30 microns in size, which can cause abrasive wear. 
4. The effective protection of materials from corrosion was confirmed by coatings obtained under conditions of self-protective high temperature synthesis.

\section{REFERENCES}

1. On predicting the life time of anticorrosion coatings on steel St3. Gorokhov E.V., Vysotsky Yu.B., Donya A.P., Sokhina S.I., Peresunko L.F. Protection of metals, 1994. T.30, No. 2. P.191-195.

2. Coking Guide Ed. O. Grosskinsky Volume 2 translation from German. M.: Metallurgy. P.523-530.

3. On the surface of the materials that are essential in the minds of the integrated influx of aggressive speeches: monograph / B.P.Sereda, L.P.Bannikov, S.V.Nesterenko, O.S.Gaidanko that. DDTU, 2019. 173p.

4. Bechter A.A., Fedkova G.Ya., Gaydenko A.S., Cheshko F.F. Prospects for expanding sales of electrode pitch at PJSC Zaporozhkoks. Coal Chemical Journal, 2019. No 1-2. P.38-44.

5. Guiding technical material: RTM 26-01-21-68. Methods of corrosion testing of metallic materials. Primary requirements. Evaluation of the results. All-Union scientific researcher and const. Institute of Chem. mechanical engineering. M, 1969.

6. Improving the corrosion resistance of steel and alloys in coal-tar processing / S.V.Nesterenko, V.M.Troshin, L.P.Bannikov, V.V.Karchakova. Coke and Chemistry, 2016. Vol. 59. No. 10. P.389-395.

7. Sereda B.P., Gaidanko O.S. Science notes: zbirnik sciences. praz LNTU. 2019. No 66. P.298-301.

8. Sereda B., Sereda D., Kryglyak I. Production of highly effective SHS coatings operating in oxidizing and corrosive environments. Material science and technology 2017. Pittsburgh. Pennsylvania USA. 2017. P.424-429.

9. Simulation and modeling of metallurgical phenomena produced on pressing in SHS-condition/ Sereda B., Sereda D., Kovalenko A., Kryglyak I. Material science and technology - 2017. Pittsburgh. Pennsylvania USA. 2017. P.727-732.

10. Sereda B., Sereda D., Sereda I. Establishment of the relationship between the microstructure characteristics and the heat resistance of silicate coatings obtained under SHS conditions. Material science and technology - 2017. Pittsburgh. Pennsylvania USA. 2017. P.412-416.

11. Sereda D., Sereda B. Corrosion Resistance and Mechanical Properties Zinc Coating Sheet Steels, Received in Conditions of Self-propagating High Temperature Synthesis. Material science and technology - 2016. Salt Lake City, Utah USA 2016. P.825-829.

12. Sereda D., Sereda B. Development of Protective Coatings Formulations Based on Boron for Units Operating at High Temperatures in Metallurgy. Material science and technology - 2016. Salt Lake City, Utah USA 2016. P.931-934.

13. Sereda D., Sereda B. Modeling deformation in material processing and laws of phasic by SHS pressing intermetallics alloys. Material science and technology. Columbus. Ohio, USA 2015. P.611-617.

14. Sereda D., Sereda B. Aluminized Multifunctional Coating on Steel in SHS Condition. Material science and technology. Pittsburgh. Pennsylvania, USA 2014. P.482486.

15. Sereda B., Sereda D. Advanced Chromoaluminizing Coatings for Wear and Heatresistance on Composite Materials under SHS. Material science and technology - 2015. Columbus, OH, USA. 1821p. P.229-232. 